\title{
ANALISIS INFORMASI CITRA ANATOMI FASE LATE ARTERY DENGAN VARIASI TIME SCAN DELAY PADA PEMERIKSAAN MSCT ABDOMEN
}

\section{ANALYSIS ANATOMICAL IMAGE INFORMATION LATE ARTERIAL PHASE WITH TIME SCAN DELAY VARIATIONS OF THE ABDOMEN MSCT EXAMINATION}

\author{
Bagus Abimanyu ${ }^{1)}$, Luthfi Rusyadi ${ }^{2)}$, Taufiq ${ }^{3)}$ \\ ${ }^{1,2)}$ Health Polytechnics of Semarang-Indonesia \\ ${ }^{3)}$ Radiology Dr. Kanujoso Djatiwibowo Balikpapan Hospital \\ e-mail: bagus_abimanyu@gmail.com
}

\begin{abstract}
Background: MSCT Abdomen late arterial phase is a radiological examination to evaluated enhancement in hypervascular lesions, stomach, bowel, pancreas parenchyma, spleen and kidney outer cortex. All the structures get bloodsupply of the artery will show an optimal increase (Smithuis, 2014). Smithuis (2014) used time scan delay 15-20 seconds. However in the Abdomen MSCT examination in the late arterial phase of Radiology Hospital Dr. Kanujoso Djatiwibowo Balikpapan used the different time scan delay. This study aimed to determine differences in contrast enhancement with time scan delay variation of contrast media and to determine the optimal time scan delay in the examination of the Abdomen MSCT late arterial phase.

Methods: The research type is quantitative experimental approach. Data are taken in October and November 2016. The research population of abdomen MSCT examination clinical intra-abdominal mass cases. Total sample are 18 people with a predetermined inclusion criteria. Time scan delay variation used are 10 seconds, 15 seconds, 20 seconds. evaluated with respondents the data is processed with statistic analysis by using different test Kruskal-Wallis followed by post hock Mann-Whitney and to get the most optimal assessment visits of mean rank the Kruskal-Wallis test.

Result: The results obtained $\mathrm{p}$ value $0,001(\mathrm{p}<0,05)$, there are shown significant differences between time scan delay 10 seconds, 15 seconds, 20 seconds at Abdomen MSCT examination in the late arterial phase of Radiology Dr. Kanujoso Djatiwibowo Balikpapan Hospital. An optimal time scan delay on Abdomen MSCT examination late arterial phase is 10 seconds premises ROI tracking on descenden aorta. From the results of tests conducted using the Kruskal-Wallis test values mean rank at the time scan delay of 10 seconds is 84,75 .

Conclusison: There is a difference significant anatomical image information between the time scan delay 10 seconds, 15 seconds, 20 seconds on MSCT Abdomen examination artery in the late phase of Radiology Dr. Kanujoso Djatiwibowo Balikpapan Hospital. assessment results are tested using the Kruskal-Wallis test followed Mann-Whitney post hock obtained p value 0.001 ( $\mathrm{p}<0.05$ ), meaning that there is a difference between the third anatomical image information with time scan delay variations. Time delay optimal scan on Abdomen MSCT examination late artery phase that time scan delay 10 seconds by tracking ROI on descenden aorta. From the results of tests conducted using the Kruskal-Wallis test values mean rank at the time scan delay of 10 seconds $84.75,56.62$ ie 15 seconds, 20 seconds, namely 22.12 .
\end{abstract}

Keywords : MSCT late phase abdominal artery, time scan delay

\section{PENDAHULUAN}

CT-scan merupakan salah satu modalitas imajing diagnostik yang menggunakan gabungan dari sinar-x dan komputer untuk mendapatkan citra atau gambar berupa variasi irisan tubuh manusia (Bontranger, 2001). CT-scan dapat digunakan untuk mediagnosa kelainan pada organ tubuh mulai dari kepala, leher, rongga dada, rongga perut, tulang belakang, dan anggota tubuh lainnya. Kelainan itu dapat berupa tumor, pendarahan maupun kelainan yang lain, juga dapat menilai struktur tulang, memeriksa kelainan paru, memeriksa pembuluh darah coroner jantung, usus besar, saluran nafas dan struktur pembuluh darah (Rasad 2000)

Media kontras yang sering digunakan dalam pemeriksaan CT-Scan adalah media kontras positif yang mengandung iodium karena lebih mengatenuasi sinar-x sehingga membuat struktur yang dilewatinya terlihat lebih padat (enhance). (Bae, 2006) menegaskan bahwa faktor-faktor yang mempengaruhi enhancement media kontras intravena pada CT Abdomen antara lain time scan delay, volume media kontras, kecepatan injeksi (flow rate), konsentrasi media kontras, larutan garam (saline flushing). Selain faktor tersebut, cardiac output, expansi plasma, extravascular redistribusi, filtrasi ginjal dan ekskresi media kontras ikut mempengaruhi derajat enhancement yang dihasilkan (Seeram, 2001).

Perbedaan tingkat enhancement media kontras dapat terjadi pada pasien dengan berat badan yang berbeda-beda dan untuk menjaga kestabilan puncak penyagatan media kontras pada pasien gemuk, yang harus dilakukan adalah meningkatkan dosis iodine (iodium) dengan menambahkan volume $(\mathrm{ml})$ dan atau konsentrasi $(\mathrm{mg} / \mathrm{ml})$. (Lipson, 2006). Menurut Heyken (2005) faktor yang sangat penting yang mempengaruhi waktu scan adalah cardiac output. Penurunan cardiac ouput menyebabkan tertundanya jalannya media kontras dalam aorta, sehingga menyebabkan tertundanya enhancement pada arteri dan hepatic parenchymal. Karena variasi substansial diantara cardiac output pasien, ini penting pada masing-masing scan delay dalam mempelajari citra dimana scan timing sangat penting. Time scan delay yang tepat pada fase post kontras berguna untuk meningkatkan 
deteksi massa, memberikan karakteristik yang lebih baik dan menentukan stadium yang lebih akurat. (Seeram, 2001).

Menurut Bae (2010) mejelaskan bahwa faktor terkait pasien yang dapat mempengaruhi peningkatan contrast enhancement yaitu berat badan dan tinggi badan serta cardiac output. Faktor pasien lain yang penting namun kurang dianggap berpengaruh yaitu usia, jenis kelamin, akses vena, fungsi ginjal, sirosis hati, hipertensi portal dan berbagai kondisi patologis lainnya.

Pemeriksaan CT-scan abdomen bertujuan untuk melihat anatomi dan patologi dari organ-organ daerah abdomen dimana gambaran hasil scanning berupa gambaran penampang crossectional. Pengambilan data akuisisinya dilakukan sebelum pemasukan kontras (pre kontras) dan sesudah pemasukan kontras (post kontras). Pada scanning post kontras dikenal fase-fase enhancement dimana pemilihan scan delay berdasarkan target yang dilihat. Fase-fase tersebut adalah fase early artery, fase late artery, fase vena porta, fase delayed. (Knolmaan, 2006)

Pada fase non enhanced $C T$ membantu dalam mendeteksi kalsifikasi pada liver, pancreas, lemak dalam tumor, lemak dalam adrenal adenoma atau myelolipoma, fatstrading seperti yang terlihat dalam peradangan seperti apendisitis, divertikulitis, infark omentum, batu ginjal, ureter dan kadang-kadang dalam CBD (Common Bile Duct). Pada fase early artery ini mendeteksi dissection aorta, bleeding artery. Pada fase late artery biasa juga disebut "fase arteri" atau "awal fase portal vena", karena beberapa peningkatan vena portal dapat dilihat. Pada fase late artery ini terjadi enhancement pada hypervascular lesion, stomach, bowel, pancreas parenchyma, spleen dan kidney outer cortex. Semua struktur yang mendapatkan bloodsupply dari arteri akan menunjukkan peningkatan yang optimal. Pada fase hepatic ini parenkim hati enhance melalui bloodsupply oleh vena portal dan akan terlihat enhance pada beberapa vena hepatika. Deteksi pada hypovasculer liver lesions : cysts, absces, metastases. Pada fase nephrogenic ini adalah ketika semua parenkim ginjal termasuk enhance medula. Hanya dalam fase ini akan dapat mendeteksi karsinoma kecil ginjal. Fase delayed kadang-kadang disebut "wash out phase" atau "fase keseimbangan". Mencuci kontras di semua struktur abdomen kecuali untuk jaringan fibrosis, karena jaringan fibrosis memiliki pencucian lambat dan akan menjadi relatif padat dibandingkan dengan jaringan normal. Deteksi pada liver: cholangiocarcinoma, fibrotic mastases, paling umum pada kanker payudara, pada ginjal transitional cell carcinoma. (Smithuis, 2014)

Pada pemeriksaan MSCT Abdomen dengan media kontras di Instalasi Radiologi RSUD Dr. Kanujoso Djatiwibowo Balikpapan, time scan delay yang digunakan pada fase late artery adalah 10 detik setelah mencapai nilai threshold dengan tracking ROI pada Aorta Ascendens setinggi carina. Sedangkan menurut Smithuis (2014) time scan delay yang digunakan pada fase late artery adalah 15-20 detik setelah bolus tracking.

\section{METODE}

Jenis penelitian yang dilakukan dalam penulisan karya tulis ilmiah ini adalah jenis penelitian kuantitatif dengan pendekatan eksperimen. Dilaksanakan pada bulan Oktober sampai November 2016, bertempat di Instalasi Radiologi RSUD Dr. Kanujoso Djatiwibowo Balikpapan, Kalimantan Timur.

Populasi dalam penelitian ini adalah semua pasien pemeriksaan MSCT Abdomen dengan kasus massa intra abdomen menggunakan teknik biphase. Dokter radiologi meminta untuk dilakukan pemeriksaan dengan fase late artery guna mengetahui tingkat contrast enhancement pada hypervasculer lesion.

Jumlah sampel yang digunakan pada penelitian ini sebanyak 18 orang pasien diambil dalam waktu satu bulan penuh. Teknik penentuan sampel pada penelitian ini adalah purposive sampling. Karena tidak dilakukan pada seluruh populasi, tapi berfokus pada target. Pengambilan sampel data dengan kriteria tertentu seperti rentang usia 30 - 70 tahun, ureum creatinin normal, tekanan darah dalam range systole 110 - $130 \mathrm{mmHg}$ dan klinis massa intra abdomen.

Subyek penelitian ini adalah 3 orang Radiolog sebagai responden dengan menggunakan kuesioner sebagai parameter penelitian. Obyek penelitian ini adalah pemeriksaan MSCT Abdomen dengan kasus massa intra abdomen.

Prosedur pemeriksaan terdiri dari :

Persiapan pasien meliputi persiapan khusus yang dilakukan pasien minum air putih $800 \mathrm{ml}-1000 \mathrm{ml}$, dibagi dalam 4 gelas (@200 - 250 ml). Pada gelas pertama diminum 1 jam sebelum pemeriksaan, gelas kedua dan gelas ketiga diminum tiap 15 menit (lapor petugas setelah minum gelas ketiga). Gelas keempat (terakhir diminum 5 menit sebelum pemeriksaan).

Persiapan umum yang dilakukan pertama mengisi Informed Consent sebelum melakukan pemeriksaan, ganti baju pemeriksaan yang telah disediakan di ruang ganti, melepas benda-benda logam yang menempel pada sekitar abdomen pasien, beri penjelasan kepada pasien tentang pemeriksaan yang akan dilakukan, dilakukan pengukuran berat badan dan tekanan darah pasien, mempersiapkan media kontras yang akan digunakan yang terdiri dari sepasang syringe injektor $200 \mathrm{cc}$ pada injektor otomatis, syringe A untuk media kontras dan syringe B untuk saline Flush $(\mathrm{NaCl})$, media kontras dan $\mathrm{NaCl}$ dimasukan kedalam masing-masing syringe tersebut, Pangkal T-connector yang bercabang dipasang pada ujung kedua syringe tersebut, Pada ujung Tconnector dipasang extention tube yang akan dismbungkan surflow yg telah terpasang.

Teknik pemeriksaan MSCT Abdomen, memposisikan pasien yang akan diperiksa dipersilahkan tidur terlentang di atas meja pemeriksaan dengan posisi feet first, kedua tangan diletakkan di atas kepala. Kaki diatur lurus pada meja pemeriksaan dan Mid Sagital Plane (MSP) di tengah meja pemeriksaan. Memposisikan obyek pada batas atas setinggi axilla dan batas bawah setinggi perineum, mid line tubuh berada di pertengahan meja, Memasukkan data pasien data 
pasien yang harus dimasukkan meliputi: nama pasien, nomor medical record (rekam medis/RM), tanggal lahir, jenis kelamin. Kemudian memilih jenis pemeriksaan MSCT Abdomen dengan kontras sesuai dengan protokol yang sudah diatur berdasarkan variasi time scan delay yaitu : Abdomen_multiphase_d10, Abdomen_multiphase_d15, Abdomen_multiphase_d20

Tabel 1. Scan Parameter Abdomen

\begin{tabular}{cc}
\hline Item & Parameter \\
\hline Program & Abdomen Multiphase \\
Eff. mAs & 200 \\
$\mathrm{kV}$ & 120 \\
Scan Time & $10,4 \mathrm{~s}$ \\
Delay & 10 detik, 15 detik, 20 detik \\
Slice & $0,75 \mathrm{~mm}$ \\
Pitch & 1,2 \\
Rotation Time & $0,5 \mathrm{sec}$ \\
Detector Configuration & $64 \times 0.6 \mathrm{~mm}$ \\
FoV & $300 \mathrm{~mm}$ \\
Image thickness & $5.0 \mathrm{~mm}$ \\
Kernel & B $30 \mathrm{f}$ \\
Windowing & Abdomen \\
\hline
\end{tabular}

Membuat Topogram diambil dengan scan lenght (range), dengan area scanning dari setinggi Th $I V$ atau axilla sampai dengan perinium yaitu AP. Tujuan pengambilan topogram dari Th $I V$ ini untuk mendapatkan area carina yang akan dilakukan acuan ROI pada pelacak bolus (bolus tracking) media kontras. Pengaturan Area Scan saat setelah topogram di peroleh kemudian menentukan daerah scan atau range yang akan discanning yaitu mulai Carina sampai perinium.

Setelah mengatur area scanning selanjutnya melakukan scanning Pre Kontras scanning polos dengan parameter yang telah ada. Kemudian dilakukan premonitoring untuk meletakkan tracking ROI, untuk pengaturan premonitoring diletakkan pada aorta descenden setinggi carina. Selanjutnya time scan delay diatur sesuai dengan variasi yang ingin dilakukan. Nilai HU ditetapkan 150 sehingga ketika HU mencapai nilai 150 scanning dilakukan secara otomatis berdasarkan time scan delay yang telah diatur.

Atur injektor dengan flowrate $3,5 \mathrm{ml} / \mathrm{s}$ dan jumlah media kontras disesuiakan dengan berat badan pasien, dalam hal ini jumlah media kontras disesuaikan dengan berat badan pasien, jika berat badan pasien $50-60 \mathrm{~kg}$ maka jumlah media kontras yang digunakan sekitar $75-90 \mathrm{ml}$.

Setelah dilakukan pemasukan media kontras selanjutnya dipantau menggunakan grafik dan angka yang terdapat pada aorta descenden yang telah ditracking. Kemudian setelah media kontras mencapai nilai threshold time scan delay berjalan sesuai dengan yang telah kita tetapkan.

Setelah scanning selesai kemudian dilakukan rekonstruksi citra di monitor 3D, slice thickness yang digunakan adalah $5 \mathrm{~mm}$, dan slice distance $5 \mathrm{~mm}$, jumlah irisan yang dihasilkan adalah untuk potongan axial sebanyak 71 irisan, untuk potongan coronal sebanyak 24 irisan, untuk potongan sagital sebanyak 24 irisan untuk kasus tertentu.

Penilain Informasi Citra Anatomi,pada tahap ini dilakukan pengisian kuisioner yang diberikan pada masing- masing radiolog. Radiograf dengan masing-masing variasi scan delay dicetak, kemudian dievaluasi oleh radiolog. Kemudian radiolog membandingkan informasi citra anatomi dengan variasi time scan delay lesi hypervascular, . Pada kuisioner yang disediakan terdapat 3 penilaian yaitu jelas dengan scor 3 , cukup jelas dengan scor 2 dan kurang jelas dengan skor 1 .

Pengolahan dan Analisis Data, dari hasil penilaian yang diakukan oleh radiolog maka analisis data yang dilakukan dengan program SPSS 16.00 for windows. Penelitian ini bertujuan untuk mengetahui paling tidak terdapat kelompok yang mempunyai perbedaan yag bermakna. Jenis pengujian yang dilakukan adalah : Uji Kappa, penilaian citra MSCT Abdomen fase late artery dilakukan oleh tiga orang dokter ahli radiologi sebagai responden. Peneliti menginginkan antar responden mempunyai realibilitas yang baik (minimal Kappa $=0,8$ ). Uji Kurskal-Willis, pengujian yang dilakukan pada penelitian ini yaitu uji Kruskal-Wallis, karena data tidak berpasangan dengan jumlah variabel lebih dari dua dan jenis data ordinal. Analisis Post Hock, analisis Post Hock untuk uji Kruskal-Wallis adalah Mann-Whitney merupakan alternatif lain untuk menguji beda mean dari dua sampel. Karena penelitian ini menggunakan tiga variabel yaitu time scan delay 10 detik, 15 detik, 20 detik, maka uji Mann Whitney dilakukan antara time scan delay 10 detik dan 15 detik, time scan delay 10 detik dan 20 detik, serta time scan delay 15 detik dan 20 detik.

\section{HASIL}

Kriteria yang dibuat berdasarkan kriteria inklusi yang telah ditetapkan peneliti meliputi usia pasien, tekanan darah pasien, hasil laboratorium ureum kreatinin serta klinis pasien.

Setiap pasien dilihat data mengenai umur, berat badan, tekanan darah, hasil laboratorium ureum kreatinin normal dan klinis pasien agar variabel-variabel tersebut dapat terkontrol. Variabel umur berguna untuk memastikan kategori pasien dewasa. Variabel berat untuk menghitung volume media kontras yang akan diberikan yaitu $1,5 \mathrm{ml} / \mathrm{kg}$ berat badan. Variabel tekanan darah (systole 110-130 mmHg) untuk memastikan cardiac output dalam keadaan baik. Variabel hasil laboratorium kreatinin normal pria $0,7-1,2 \mathrm{mg} / \mathrm{dl}$ dan wanita $0,5-0,9 \mathrm{mg} / \mathrm{dl}$ sedangkan ureum pria 18 - $55 \mathrm{mg} / \mathrm{dl}$ dan wanita 15 - $40 \mathrm{mg} / \mathrm{dl}$, untuk memastikan filtrasi dan eksitasi ginjal baik. Variabel klinis pasien yang digunakan yaitu pada pasien dengan klinis tumor atau massa intra abdomen.

Dalam penelitian ini jumlah sampel yang digunakan sebanyak 18 orang dengan rentang usia 35 - 65 tahun. Dari 18 sampel tersebut terdiri atas laki-laki dan perempuan. Tinggi badan antara $150-165 \mathrm{~cm}$, berat badan sekitar $50-60 \mathrm{~kg}$, hal ini memudahkan dalam menentukan jumlah media kontras yang diberikan. Tekanan darah semua sampel semuanya normal, sedangkan ureum kreatinin sebanyak 11 orang pasien dalam batas normal, 4 orang pasien denngan ureum rendah (tidak normal), 3 orang pasien dengan kreatinin rendah (tidak normal), namun dokter radiologi mampu menjamin untuk tetap dilaksanakannya pemeriksaan MSCT Abdomen. 
Penelitian dilakukan pada 18 orang sampel dengan variasi yang berbeda beda. Variasi yang dilakukan pada 6 orang pasien dengan time scan delay 10 detik, 6 orang pasien dengan time scan delay 15 detik dan 6 orang pasien dengan time scan delay 20 detik.

Jumlah sampel tiap variasi sama yaitu 6 pasien. Klinis pada pemeriksaan MSCT abdomen semua sampel sama yaitu massa intra abdomen, flow rate yang digunakan $3,5 \mathrm{ml} / \mathrm{s}$, jumlah media kontras yang digunakan $80 \mathrm{ml}$ dikarenakan berat badan masing-masing sampel tidak jauh berbeda, $\mathrm{NaCl}$ yang digunakan sebelum media kontras masuk sebanyak 20 $\mathrm{ml}$ dan setelah media kontras masuk sebanyak $40 \mathrm{ml}$. Tracking ROI diletakkan pada aorta desendens setinggi carina dan nilai threshold yang digunakan 150 .

Penilaian Citra MSCT Abdomen fase late artery, uji konsistensi Cohen's Kappa merupakan ukuran yang menyatakan konsistensi pengukuran yang dilakukan dua orang penilai atau konsistensi antar dua metode pengukuran atau dapat juga mengukur konsistensi antar dua alat pengukuran. Koefisien Cohen's Kappa hanya diterapkan pada hasil pengukuran data kategorik. Berikut hasil dari uji Kappa.

Tabel 2. Hasil Uji Kappa

\begin{tabular}{cccc}
\hline No. & Uji & Value & Keterangan \\
\hline 1 & Kappa & 0,943 & Realibilitas baik \\
\hline
\end{tabular}

Berdasarkan hasil dari uji Kappa di atas dapat diketahui bahwa nilai Kappa sebesar 0,943. Dengan nilai Kappa sebesar 0,943 maka dapat dikatakan responden mempunyai realibilitas yang baik (minimal Kappa $=0,8$ ) yang artinya terdapat kesepakatan yang signifikan antara masing-masing Responden.

Perbedaan Informasi Citra Anatomi dengan time scan delay, untuk mengetahui perbedaan informasi citra anatomi pada masing-masing time scan delay maka dilakukan uji Krukal Wallis. Pengujian ini bertujuan untuk mengetahui bermakna atau tidaknya perbedaan informasi citra anatomi terhadap 3 variasi tersebut, perbedaan tersebut dapat dilihat pada tabel berikut :

Tabel 3. Hasil Uji Kruskal Wallis dengan Variasi Time Scan Delay

\begin{tabular}{cccc}
\hline No & Uji & P value & Keterangan \\
\hline 1 & Kruskal-Wallis & 0,001 & Ada perbedaan \\
\hline
\end{tabular}

Tabel 3. merupakan hasil pengujian Kruskal Wallis, dari hasil pengujian didapat nilai $p$ value 0,001 maka $(p<0,05)$. Hal tersebut menunjukkan adanya perbedaan informasi citra anatomi pada variasi time scan delay yang digunakan. Maka Ha diterima artinya terdapat perbedaan informasi citra anatomi antara 3 variasi time scan delay tersebut.

Selanjutnya dilakukan analisis Post Hock. Analisis Post Hock untuk uji Kruskal-Wallis adalah Mann-Whitney. Jadi perlu melakukan uji Mann Whitney antara time scan delay 10 detik dengan time scan delay 15 detik, time scan delay 10 detik dengan time scan delay 20 detik, time scan delay 15 detik dengan time scan delay 20 detik. Hasil uji Mann Whitney dapat dilihat pada tabel sebagai berikut :

\begin{tabular}{cccc}
\multicolumn{4}{c}{ Tabel 4. Hasil Uji Mann Whitney dengan Variasi Time Scan Delay } \\
\hline No & Time Scan Delay & $\mathrm{p}$ value & Keterangan \\
\hline 1 & $\begin{array}{c}\text { 10 Detik vs 15 } \\
\text { Detik }\end{array}$ & 0,001 & Ada perbedaan \\
2 & $\begin{array}{c}\text { 10 Detik vs } 20 \\
\text { Detik }\end{array}$ & 0,001 & Ada perbedaan \\
3 & $\begin{array}{c}\text { 15 Detik vs } 20 \\
\text { Detik }\end{array}$ & 0,001 & Ada perbedaan \\
\hline
\end{tabular}

Dengan uji Mann Whitney diperoleh hasil bahwa Secara statistik, terdapat perbedaan informasi citra anatomi antara time scan delay 10 detik dengan time scan delay 15 detik karena nilai $\mathrm{p}$ value $=0,001 \quad(\mathrm{p}<0,05)$. Secara statistik, terdapat perbedaan informasi citra anatomi antara time scan delay 10 detik dengan time scan delay 20 detik karena nilai $\mathrm{p}$ value $=0,001 \quad(p<0,05)$. Secara statistik, terdapat perbedaan informasi citra anatomi antara time scan delay 15 detik dengan time scan delay 20 detik karena nilai $\mathrm{p}$ value $=0,001(\mathrm{p}<0,05)$.

Time scan delay yang optimal pada pemeriksaan MSCT Abdomen, untuk mengetahui time scan delay yang optimal pada pemeriksaan MSCT abomen dapat diketahui pada mean rank uji Kruskal Wallis. Nilai mean rank menunjukkan peringkat rata-rata masing-masing perlakuan. Hasil analisi data statistik yang diperoleh adalah sebagai berikut :

Tabel 5. Hasil Uji Mean Rank Kruskal-Wallis

\begin{tabular}{ccc} 
& Tabel 5. Hasil Uji Mean Rank Kruskal-Wallis \\
\hline No. & Time Scan Delay & Mean Rank \\
\hline 1 & 10 Detik & 84,75 \\
2 & 15 Detik & 56,62 \\
3 & 20 Detik & 22,12 \\
\hline
\end{tabular}

Dari hasil tersebut pada time scan delay 10 detik memiliki mean rank paling tinggi yaitu 84,75, 15 detik memiliki mean rank 56,52 dan 20 detik memiliki mean rank 22,12 .

Dari hasil uji Kruskal-Wallis dilanjutkan dengan uji post hock Mann-Whitney terdapat perbedaan informasi citra anatomi antara ketiga variasi time scan delay dengan nilai $\mathrm{p}$ value $=0,001 \quad(\mathrm{p}<0,05)$. Pada time scan delay 10 detik memiliki mean rank paling tinggi yaitu 84,75, 15 detik memiliki mean rank 56,62 dan 20 detik memiliki mean rank 22,12, sehingga berdasarakan hasil uji statistik inferensial time scan delay yang optimal yaitu pada time scan delay 10 detik. Selain itu analisis deskriptif rentang penilaian yang jelas pada time scan delay 10 detik dengan rata-rata 17,6.

\section{DISKUSI}

Berdasarkan hasil pengujian menggunakan uji beda Kruskal-Wallis dilanjutkan uji post hock Mann-Whitney dengan $p$ value 0,001 didapat kesimpulan bahwa Ho ditolak dan Ha diterima maka ada perbedaan informasi citra anatomi antara variasi time scan delay pada pemeriksaan MSCT Abdomen fase late artery. Hasil penilaian responden cenderung tinggi pada variasi time scan delay 10 detik.

Time scan delay merupakan waktu jeda setelah media kontras mencapai nilai threshold, ketika media kontras telah 
mencapai nilai threshold maka CT-scan akan mulai mengakuisisi gambar secara otomatis sesuai dengan time scan delay yang telah ditentukan. Menurut Bae (2006) time scan delay memberikan pengaruh pada pencapaian puncak penyangatan yang dihasilkan, penggunaan time scan delay yang tepat maka akan memberikan nilai enhancement yang tinggi sehingga bagian dari pembuluh darah dan massa dapat dievaluasi secara maksimal maka informasi citra anatomi yang diberikan dapat menegakkan diagnosa. Dalam menentukan time scan delay terdapat beberapa hal yang harus diperhatikan yaitu jika penentuan time scan delay yang terlalu cepat akan menyebabkan subpeak, artinya media kontras belum mencapai puncak penyangatan maksimum, sedangkan jika pengaturan time scan delay yang terlalu lama maka media kontras akan terlewat sehingga tidak didapatkan puncak penyangatan.

Pada pemeriksaan MSCT Abdomen fase late artery menurut Smithuis (2014) rentang time scan delay yang digunakan pada pemeriksaan MSCT Abdomen fase late artery yaitu 15 - 20 detik dengan tracking ROI pada aorta desenden. Perbedaan letak ROI dapat mempengaruhi time scan delay yang digunakan. Sedangkan pada penelitian ini penulis melakukan modifikasi protokol yaitu menggunakan time scan delay 10 detik, 15 detik, 20 detik dengan letak tracking ROI pada Aorta descenden sehingga time scan delay yang digunakan lebih pendek tetapi tidak dapat mentoleransi jika terjadi keterlambatan saat akuisisi data pada saat media kontras mencapai nilai threshold.

Selain time scan delay menurut Bae (2006) contrast enhancement dipengaruhi oleh beberapa faktor yaitu konsentrasi media kontras, flow rate, volume media kontras dan saline flush. Konsentrasi media kontras memiliki pengaruh pada peningkatan pencapaian puncak penyangatan, semakin tinggi konsentarsi media kontras maka gambaran semakin enhance. Pada penelitian ini pemeriksaan MSCT Abdomen menggunakan konsentrasi media kontras 370 $\mathrm{mgI} / \mathrm{ml}$. Flow rate memberi pengaruh kepada citra dimana penggunaan flow rate tinggi akan memberi pengaruh pada pencapaian puncak penyangatan, tingkat enhancement, tingkat enhancement akan tinggi tetapi waktu lebih pendek, pada pemeriksaan MSCT Abdomen rutin flow rate yang digunakan $4-5 \mathrm{ml} / \mathrm{s}$, pada penelitian ini flow rate yang digunakan 3,5 $\mathrm{ml} / \mathrm{s}$ dengan pertimbangan konsentrasi media kontras yang digunakan $370 \mathrm{mgI} / \mathrm{ml}$. Volume media kontras merupakan jumlah media kontras yang diinjeksikan kepada pasien, banyak sedikitnya media kontras yang dimasukkan ke dalam tubuh diperngaruhi oleh berat badan pasien itu sendiri, maka penulis memilih sampel dengan berat badan yang hampir sama sehingga volume media kontras yang diberikan juga sama. Saline flush membantu dalam memperlancar aliran darah, selain itu saline flush juga membantu mendorong media kontras agar terjadi pencapaian puncak penyangatan yang tepat. Jumlah saline flush yang digunakan sebelum media kontra masuk yaitu $20 \mathrm{ml}$ dan $40 \mathrm{ml}$ setelah media kontras masuk.

Menurut penilaian responden gambaran pada time scan delay 10 detik dibandingkan 20 detik terlihat jauh berbeda terutama pada organ hepar, media kontras tampak sudah banyak terserap dan media kontras sudah masuk fase hepatika.

Menurut penulis terdapat perbedaan informasi citra anatomi hasil citra pada time scan delay 10 detik, 15 detik, 20 detik terutama pada time scan delay 10 detik dan 20 detik. pada saat melakukan rekonstruksi MPR, pada time scan delay 15 detik media kontras yang masuk sudah mulai enhance di daerah hepar akan tetapi pada pasien tertentu dengan time scan delay 15 detik belum enhance pada daerah hepar. Sedangkan pada time scan delay 20 detik, kontras sudah enhance pada hepar sehingga citra yang dihasilkan sama dengan citra fase hepatika.

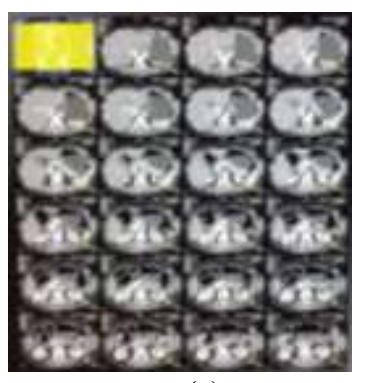

(a)

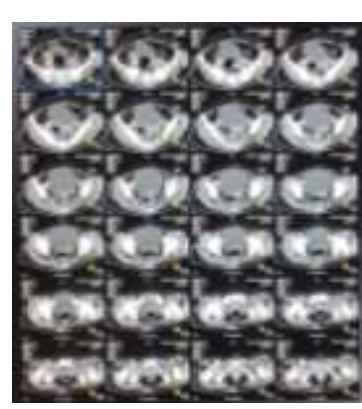

(c)

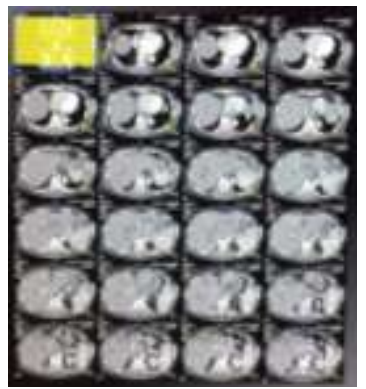

(a)

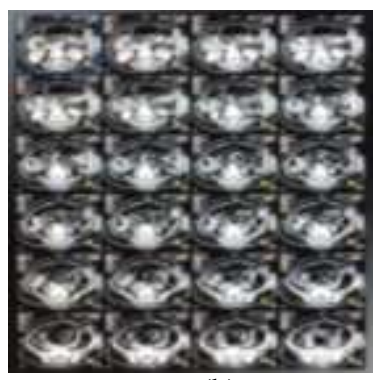

(b)

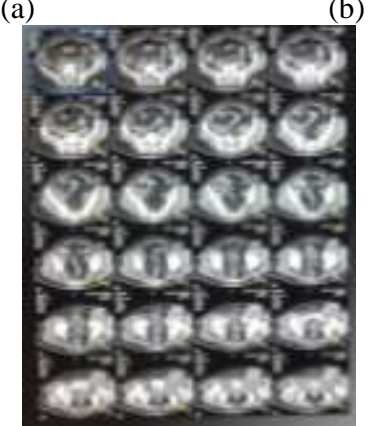

(c) 
Gambar 2. (a)(b)(c) Citra Time Scan Delay 15 Detik

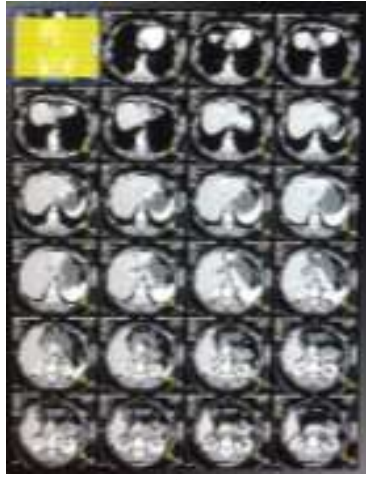

(a)

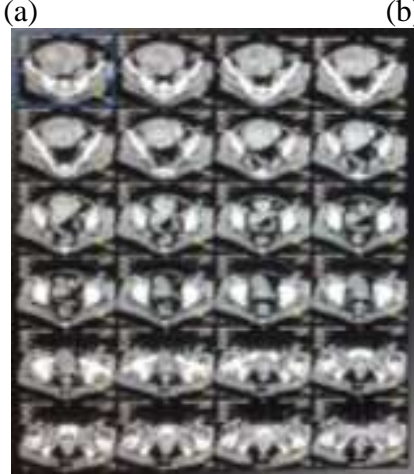

(c)

Gambar 3. (a)(b)(c) Citra Time Scan Delay 20 Detik

Dari hasil pengujian yang dilakukan untuk mengetahui time scan delay yang optimal secara keseluruhan pada informasi anatomi yang dinilai dengan menggunakan uji Kruskal-Wallis dilanjutkan dengan uji post hock MannWhitney, maka didapat mean rank tertinggi yaitu 84,75 pada time scan delay 10 detik dengan tracking ROI pada aorta descenden.

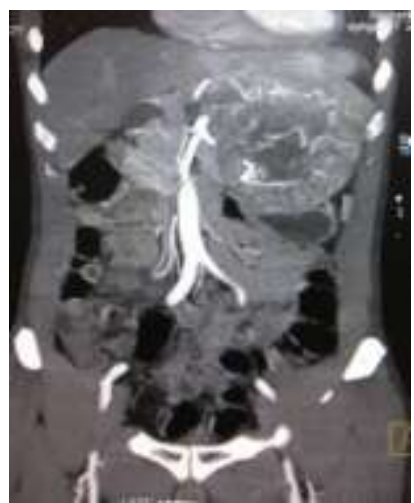

(a)

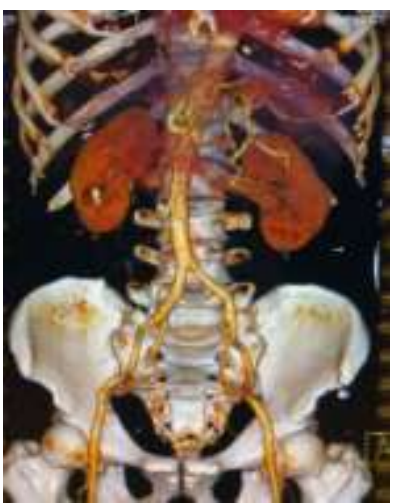

(b)
Gambar (a) Citra potongan coronal MIP time scan delay 10 detik, b. Citra VRT time scan delay 10 detik

Menurut Smithuis (2014) waktu scanning adalah penting dalam rangka mendapatkan saat kontras maksimal untuk membedakan antara lesi dan parenkim normal. Scanning menunjukan perbandingan fase early artery dan fase late artery. Pada fase late artery dapat dengan jelas mengidentifikasi beberapa massa tumor. Pada fase late artery, waktu yang paling optimal pada detik ke 35, jadi start scanning kira-kira pada detik 25 dan berakhir pada detik ke 45. Pada detik ke 35 lesi hypervasculer seperti Hepatocelluler Carcinoma (HCC), Hiperplasia Nodula Focal, Adenoma dan hemangioma akan enhance secara optimal, sedangkan parenkim yang normal hanya menunjukkan peningkatan minimal.

Metode yang digunakan oleh Smithuis (2014) dalam jurnalnya seperti yang dijelaskan diatas adalah metode fix time delay, sedangkan dengan menggunakan metode bolus tracking, scanning dimulai antara 15 detik sampai 20 detik setelah tercapai nilai threshold. Pada penelitian ini penulis menggunakan metode bolus tracking, rata-rata pencapaian nilai threshold adalah 17 detik sampai 20 detik, sehingga scanning dimulai pada detik ke 27 sampai detik ke 37 .

Menurut penulis pada time scan delay 10 detik dengan tracking ROI pada aorta descenden merupakan waktu yang paling optimal karena pada pemeriksaan MSCT Abdomen fase late artery dapat memberikan informasi citra anatomi pada lesi hypervascular dan pembuluh darah yang memperdarahi lesi tersebut. Selain itu berdasarkan hasil penelitian pada time scan delay 10 detik didapat hasil mean rank uji Kruskal-Wallis tertinggi dibanding mean rank 15 detik dan 20 detik. Hal ini berbanding lurus dengan time scan delay yang pendek maka memberikan informasi anatomi yang optimal. Time scan delay yang dapat digunakan untuk pemeriksaan MSCT Abdomen fase late artery untuk hasil yang optimal dapat menggunakan time scan delay 10 detik dan 15 detik masih bisa digunakan, akan tetapi untuk penggunaan time scan delay 15 detik lebih dipetimbangkan lagi untuk ketepatan informasi citra anatomi pada organ yang diperiksa.

\section{SIMPULAN}

Ada perbedaan informasi citra anatomi yang signifikan antara time scan delay 10 detik, 15 detik, 20 detik. pada pemeriksaan MSCT Abdomen fase late artery di Instalasi Radiologi RSUD Dr. Kanujoso Djatiwibowo Balikpapan. hasil penilaian yang diuji dengan menggunakan uji KruskalWallis dilanjutkan uji post hock Mann-Whitney didapat $\mathrm{p}$ value $0.001(\mathrm{p}<0.05)$ artinya terdapat perbedaan informasi citra anatomi antara ketiga variasi time scan delay.

Time scan delay yang optimal pada pemeriksaan MSCT Abdomen fase late artery yaitu time scan delay 10 detik dengan tracking ROI pada aorta descenden. Dari hasil uji yang dilakukan dengan menggunakan uji Kruskal-Wallis nilai mean rank pada time scan delay 10 detik 84,75, 15 detik yaitu $56,62,20$ detik yaitu 22,12.

\section{DAFTAR PUSTAKA}

Bae, Kyongtae. 2010. Intravenous Contrast Medium Administration and Scan Timing at CT : Consideration and Approaches, Departement of Radiology, University of Pittsburgh School of medicine. http://pubs.rsna.org/doi/abs/10.1148/radiol.10090908, 27 Agustus 2016

Ballinger, P. W. 2003. Merril's Atlas of Radiographic Position and Radiologic Procedures. Edisi X. Volume III. Mosby Inc : Missouri. 
Bontrager, Kenneth, L. 2001. Textbook of Radiographic Positioning and Related Anatomi. Fifth edition. Mosby Inc. Missiouri.

Bushberg, M. L. 2003. The Essential Phisics of medical Imaging, Second Edition. Lippincot Williams \& Wilkins : Philadelphia.

Bushong, Steward C. 2001. Radiologic Science for Technologist. Mosby Inc : Missouri.

Corwin, J. Elizabeth. 2009. Buku Saku Patofisiologi. Buku Kedokteran, EGC: Jakarta.

Galanski and Prokop. 2003. Principles and Techniques of images Reconstruction with CT in Cerebral Computed Tomography, Second Edition. WB Saundders Company : Philadelphia.

Heiken, Jay P. 2005. Multidetector-Row Comupted Tomography Scanning and Contrast Protocols. Springer : Milan, Berlin, Heidelberg, New York.

Irianto, Koes. 2014. Anatomi dan Fisiologi. Alfabeta : Bandung.

Jaengsri, N, MSc. 2004. Protocol CT Technique. Radiology Departement of Talesthine Hospital.

Knollmann, Friedrich. MD. 2006. Multislice CT : Principle and Protocol First Edition. Saunders Elsevier : Philadelphia.

Lipson A Scott. 2006. MDCT and 3D Workstations. Springer Science+Business Media Inc.

Nesseth, R. 2009. Procedures and Documentation for CT and MRI. MC GrwHill Medical Publishing Division : Kansas.

Pierce, E.C. 2002. Anatomi dan Fisiologi untuk Paramedis. Gramedia Pustaka Utama : Jakarta.

Rasad, S. 2000. Radiologi Diagnostik, Cetakan kedua. Balai penerbit FKUI : Jakarta.

Seeram, Euclid, RT. 2001. Computed Tomography, Physical Principle, Clinical Application and quality control, Second edition. WB Saunder Company : Philadelphia.

Sloane E. 2003. Anatomi dan Fisiologi untuk Pemula. EGC. Jakarta.

Smelster, Suzanne C. 2001. Keperawatan Medikal Bedah, Edisi 8, Vol. 2. EGC : Jakarta.

Smithuis, Robin. 2014. CT Contrast injection and Protocols, Radiology departement of the Rijnland Hospital in Leiderdorp, the Netherlands http://www.radiologyassistant.nl/en/p52c04470dbd5c / ct-contrastinjection-and-protocols.html, 26 Agustus 2016.

Snell, S, Richard. 2000. Clinical Anatomy For Medical Student. 6th ed. EGC : Jakarta. 